\title{
A Pilot Study of the Development of Empathy within a Service-learning Trip from a Qualitative Perspective
}

\section{Linjue Wang, The Ohio State University}

Linjue Wang is currently a graduate research associate in engineering education department at The Ohio State University, USA. She received her B.E. in Built Environment \& Equipment Engineering from Tsinghua University, China. She has various service learning experiences as volunteer and curriculum designer in high schools from undeveloped areas in China. Her research interests now focus on servicelearning and community engagement, as well as empowering engineering education in high schools in rural areas.

\section{Mr. Turhan Kendall Carroll, The Ohio State University}

Turhan Carroll is currently a graduate research associate in the engineering education department at The Ohio State University, Columbus, OH. He received BS degrees in Physics and Applied Mathematics from North Carolina State University. He also worked for approximately 7 years as an engineer performing research in magneto-photonics. His research interests now focus on broadening participation in engineering via the use of informal education.

\section{Dr. David A. Delaine, The Ohio State University}

Dr. David A. Delaine is an Assistant Professor at The Ohio State University Department of Engineering Education. Within this newly formed department he strives to creatively impact society through investigating the intersections of engineering, education, and social need through research on community engagement and collaborative processes within informal learning. He has obtained a Ph.D. in electrical engineering from Drexel University, in Philadelphia, USA and served as a Postdoctoral Fulbright Scholar at the Escola Politécnica da Universidade de São Paulo. Dr. Delaine is a co-founder and past president of the Student Platform for Engineering Education Development (SPEED) and has served two terms as an executive member of the International Federation of Engineering Education Societies (IFEES) as a Vice President for Diversity \& Inclusion. He is investigating university-community engagement as empowerment settings and working to further the research agenda of the global community of practice within Diversity and Inclusion in Engineering Education. His research laboratory aims to support an inclusive, global pipeline of STEM talent and to unify the needs of the engineering education stakeholders in order for engineering education to more accurately reflect societal needs. Diversity and inclusion, university/community engagement, informal learning, action research, and student led initiatives fall within the scope of his academic endeavors. 


\title{
A pilot study of the development of empathy within a service- learning trip from a qualitative perspective
}

\begin{abstract}
Qualitative outcomes of a pilot study which seeks to investigate the ways and extent to which service-learning impacts the development of empathy in undergraduate engineering students are presented. Service-learning is an experiential education pedagogy in which students engage in activities designed to tackle community needs within structured opportunities to promote learning and development. Community service, teamwork, problem-solving, and reflection are common elements within service-learning activities. This educational approach can provide students with real-world scenarios that connect classroom theory and knowledge to community needs.

A brief literature review on service-learning within engineering education, is presented alongside brief background on the meaning of empathy. This is followed by initial qualitative findings around a service-learning trip within an undergraduate engineering course involving 13 student participants. The findings indicate service-learning in a foreign community can serve as a platform for the development of empathy in engineering undergraduates. The development of empathy can be fostered within three main findings: group dynamics, interactions with the community, and individual interpretation of the service-learning experience through selfreflection. This paper concludes with a discussion on how these three findings collectively influence the development of empathy in students. This paper provides a qualitative approach to contextualizing the development of empathy as a learning outcome for engineering educators interested in service-learning.
\end{abstract}

\section{Introduction}

In a globalized world, engineers are often confronted with increasingly socio-technical, multifacetted, and ill-defined challenges [1]. These challenges require that engineers recognize specific needs and constraints, leverage the perspectives of multiple stakeholders, and work effectively within diverse, multidisciplinary teams [2]. These factors, all of which are viewed as critical, are influencing an expansion of engineering undergraduate curricula in order to develop technical professionals who exhibit appropriate professional skills within an appropriate timeframe [3]. While the technical core of the engineering curriculum has been maintained as a primary element of engineering degrees, increasing attention is being focused on the development of professional skills and the use of holistic approaches within engineering education [4], [5]. Service-learning, in which student learning outcomes are blended with community interactions, provides an experiential learning opportunity for undergraduate students to navigate the complexities of the engineering and address societal needs [6], while developing technical and professional skills.

\subsection{Service-learning within engineering}

Service-learning, an experiential learning pedagogy, has been defined in several ways [7]. The most commonly accepted academic definition is from Bringle \& Hatcher [8, p. 112]: "Course- 
based, credit bearing educational experience in which students participate in an organized service activity that meets identified community needs, and reflect on the service activity in such a way as to gain further understanding of course content, a broader appreciation of the discipline, and an enhanced sense of civic responsibility". In 1995, the Engineering Projects in Community Service Program (EPICS) became the first service-learning program integrated into an engineering curriculum, which provided an innovative educational experience for engineering undergraduates at Purdue University [9]. Service-learning has since strongly emerged as an important complement to classroom-based engineering pedagogy.

When performed effectively, it has been shown that engineering students can learn the same amount of knowledge and skills through service-learning as they can from traditional informal education models as project-based learning [10]. Further, service-learning has been shown to promote the development of professional skills, such as communication, social responsibility, problem solving, and critical thinking among engineering students [11]. Service-learning has shown positive effects on student social-emotional skills such as personal, moral, and interpersonal development [12]. As service-learning requires students to understand the real community need, this experiential learning approach aims to push students to use their technical skills to meet needs outside of the campus setting. It can also help them understand the impact of engineering designs on society [13]. It has been suggested that service learning participation, alongside personal reflection, can promote the development of empathy in engineering students [14].

\subsection{Empathy}

Since its integration into the English language in the early $20^{\text {th }}$ century, the word empathy has been a complex, multi-dimensional concept. Empathy has been explored and conceptualized across multiple disciplines [15] including cognitive neuroscience [16], social psychology [17], and behavioral science [18]. In daily language, the Oxford English Dictionary defines empathy as "the ability to understand and share the feelings of another [19]." There is often confusion between the words sympathy and empathy, both of which involve "shared feelings". The difference between these two is that empathy distinguishes between the self and the other within these shared feelings, where the empathizer maintains the "as if they were my own" element of another person's experience [20]. In the field of social work, empathy is defined as a core skill and orientation of its practitioners. This approach can inform engineering education which similarly focuses on developing engineers as functioning practitioners [21]. A functioning practitioner approach aligns with empathic engineering design where engineers consider the needs and perspectives of the end-users throughout the design process [22].

In engineering education, empathy is increasingly recognized as an important construct in preparing engineers abilities to respond to $21^{\text {st }}$ century challenges [23]-[25]. Empathy impacts communication [26], design processes [27], professional success [28], ethics [29], and the overall culture of engineering [24]. In this paper, a framework of empathy developed within the neurosciences is adopted. Decety \& Moriguchi [30] neuroscience approach to empathy has established four components of empathy: affective sharing, self-awareness, emotion regulation, perspective taking \& mental flexibility. Affective sharing means one can reflect upon the feelings of another. Self-awareness allows one to distinguish the self from the experience of another. 
Perspective taking \& mental flexibility means one can imagine and take the other's perspective without losing sense of the self. Emotion regulation provides for an individual to cognitively regulate emotion perceived in others without being affected. Further definition of these four constructs are illustrated with example excerpts in Table 4. This framework is well suited for the engineering education context because its constructs are observable skills allowing us to study empathy development as an educational outcome.

While literature on the theoretical model of empathy in engineering education exists [24], [25], [31], the role of empathy within a practical learning context has received limited attention. For instance, Hess et.al. investigated empathic perspective-taking in the learning context of engineering ethics course [32]. This pilot study analyzes students' experience within a service learning activity to explore the development of empathy in this context. The purpose of this paper is to provide a nuanced understanding of service-learning as a platform for empathy development. The research design is structured to inform the research question: How can an international, undergraduate-engineering service-learning trip contextualize student development of empathy? This paper reports on the qualitative portion of a mixed methods study through analysis of students' written reflections on-site and a focus group interview through a pilot study.

\subsection{Research background}

The service-learning experience investigated in this study is part of a semester-long, creditbearing elective engineering course at a large Mid-Western university. This course was purposefully selected for this pilot study because it is a long-running course (initially established in 2003) and has continuously partnered with the same community. The course is based on a project-based learning pedagogy (PBL), which is a form of situated-learning designed to help students construct more understanding by working on projects in real-world contexts while applying multiple skills [33]. Within this course, the real-world context was provided through a week-long service-learning trip to Montaña de Luz (MdL, http://www.montanadeluz.org) at a center for children who have been effected by HIV/AIDS in Honduras.

This pilot study was conducted in the spring 2017 semester, with 14 students enrolled in the course. During the course, the students were required to prepare for a group project during the semester and implement the project during the service-learning trip to MdL. Upon return, the students deliver a presentation on the final project implementation and deliverables, all of which earns them credit within the course towards earning their undergraduate degrees. All 14 students were split into four project groups as shown in Table 1. One student did not travel to Honduras and thus did not participate in the research.

Table 1. Projects assigned within the service-learning course

\begin{tabular}{|c|c|}
\hline $\begin{array}{l}\text { Group } \\
\text { Number }\end{array}$ & Project \\
\hline 1 & Solar panel installation \\
\hline 2 & Civil engineering of terraced fields \\
\hline 3 & K-12 STEM educational outreach \\
\hline 4 & Wind turbine with LED electrical installation \\
\hline
\end{tabular}


Each project group was assigned a project that was developed in collaboration between the representatives of the local community/MdL and the instructors who had been familiar with the community in MdL. The goal of these projects was to support the development of solutions to local needs within the MdL community in Honduras.

The entire course was not a part of the research study's structure, but only the 10-day service learning experience. The participating students selected and voluntarily enrolled in this course as a credit-bearing engineering elective. Prior to the trip, the students were made aware of the opportunity to participate in this research study. The research was presented as an investigation into service-learning and engineering practice. They were not made directly aware that the pilot study involved empathy, nor were they specifically taught content about empathy. The demographics of the students who participated in this service-learning trip, including age, gender, school year, ethnicity and major were presented in Table 2.

Table 2. Participant Demographics $(\mathrm{n}=14)$

\begin{tabular}{|c|c|c|c|}
\hline & & $n$ & $\%$ \\
\hline \multirow[t]{3}{*}{ Age } & $18-20$ & 5 & 38.5 \\
\hline & $20-22$ & 7 & 53.8 \\
\hline & $22-24$ & 1 & 7.7 \\
\hline \multicolumn{4}{|c|}{ School Year } \\
\hline & First & 2 & 15.4 \\
\hline & Second & 3 & 23.1 \\
\hline & Third & 5 & 38.5 \\
\hline & Fourth & 2 & 15.4 \\
\hline & Fifth + & 1 & 7.7 \\
\hline Race & White & 13 & 100.0 \\
\hline \multicolumn{4}{|c|}{ Gender } \\
\hline & Male & 6 & 46.2 \\
\hline & Female & 7 & 53.8 \\
\hline \multicolumn{4}{|c|}{ Major } \\
\hline & Civil Engineering & 1 & 7.7 \\
\hline & Biomedical Engineering & 1 & 7.7 \\
\hline & Industrial \& Systems Engineering & 1 & 7.7 \\
\hline & Chemical Engineering & 4 & 30.8 \\
\hline & Environmental Engineering & 1 & 7.7 \\
\hline & Electrical and Computer Engineering & 1 & 7.7 \\
\hline & Computer Science Engineering & 3 & 23.1 \\
\hline & Undecided Engineering & 1 & 7.7 \\
\hline
\end{tabular}

All participants were undergraduate students from first year to fifth year, with different majors across the engineering field. The extent to which students had previous experience within service-related work is shown in Table 3. 
Table 3. Previous Service related background $(n=14)$

\begin{tabular}{lccccc}
\hline & $\begin{array}{c}\text { Strongly } \\
\text { Disagree } \\
n(\%)\end{array}$ & $\begin{array}{c}\text { Somewhat } \\
\text { Disagree } \\
n(\%)\end{array}$ & $\begin{array}{c}\text { Neither Agree } \\
\text { nor Disagree } \\
n(\%)\end{array}$ & $\begin{array}{c}\text { Somewhat } \\
\text { Agree } \\
n(\%)\end{array}$ & $\begin{array}{c}\text { Strongly } \\
\text { Agree } \\
n(\%)\end{array}$ \\
\hline $\begin{array}{l}\text { I have engaged in } \\
\text { community service } \\
\text { projects in the past. }\end{array}$ & $0(0.00 \%)$ & $1(7.69 \%)$ & $0(0.00 \%)$ & $4(30.77 \%)$ & $8(61.54 \%)$ \\
\hline & No & Yes & $\begin{array}{c}\text { No } \\
\text { Response } \\
n(\%)\end{array}$ & \\
\hline $\begin{array}{l}\text { Has your previous } \\
\text { international travel } \\
\text { involved service work? }\end{array}$ & & $n(\%)$ & $n(\%)$ & $1(7.69 \%)$ & \\
\hline
\end{tabular}

As shown, at least half of the participants in this service-learning trip had prior exposure to service-related experience: $61.5 \%$ (8 out of 13 ) of the students have engaged in community service projects in the past. But, $75 \%$ (9 out of 12) of the students reported that they had not participated international service work. This indicates that though most students have been exposed to prior service experience, they have not been exposed to service within a foreign community. A survey prompt investigated if students had taken part or are currently active in any student organizations. Data shows that 53.8\% (7 out of 13) of the students had participated in student organizations that have some alignment with community engagement and servicelearning activities, such as humanitarian/peace/green engineering. This indicates that these students are inclined to service activities perhaps resulting in a predisposition for the development of empathy or increased potential for empathy development within this particular population.

While on-site in Honduras, the students were integrated into the Montaña de Luz community. They spent the week primarily at the MdL center, eating most of their meals as well as sleeping there. They implemented their group projects, spent time with children, took a field trip to a local cigar factory and a national park with a well-known waterfall, and visited the local university. Some students also visited a local K-12 school. Three faculty members facilitated the activities on-site and were fully embedded in all activities.

\section{Research Method}

A convergent mixed methods design, shown in Figure 1, was used within the pilot study. This design was selected for its effectiveness in developing a holistic understanding by collecting both quantitative and qualitative data, where each component provides a partial but complementary view of the studied phenomena [34]. The overall design of this mix method research includes, a qualitative approach, where students' written reflections and a focus group interview are collected and analyzed, and a quantitative approach, where pre- and post-service learning activity quantitative assessments are used to triangulate qualitative findings around empathy development. The quantitative assessment uses three different scales, including Davis' Interpersonal Relativity Index [35] and SREIT [36], and Hess/Strobel Empathy and Care in Engineering [37] designed to measure student levels of empathy before and after the servicelearning experience. Only the qualitative outcomes are presented in this paper. This is done to 
leverage and focus on the rich and thick description of student's reflections to development of empathy during the service-learning trip.

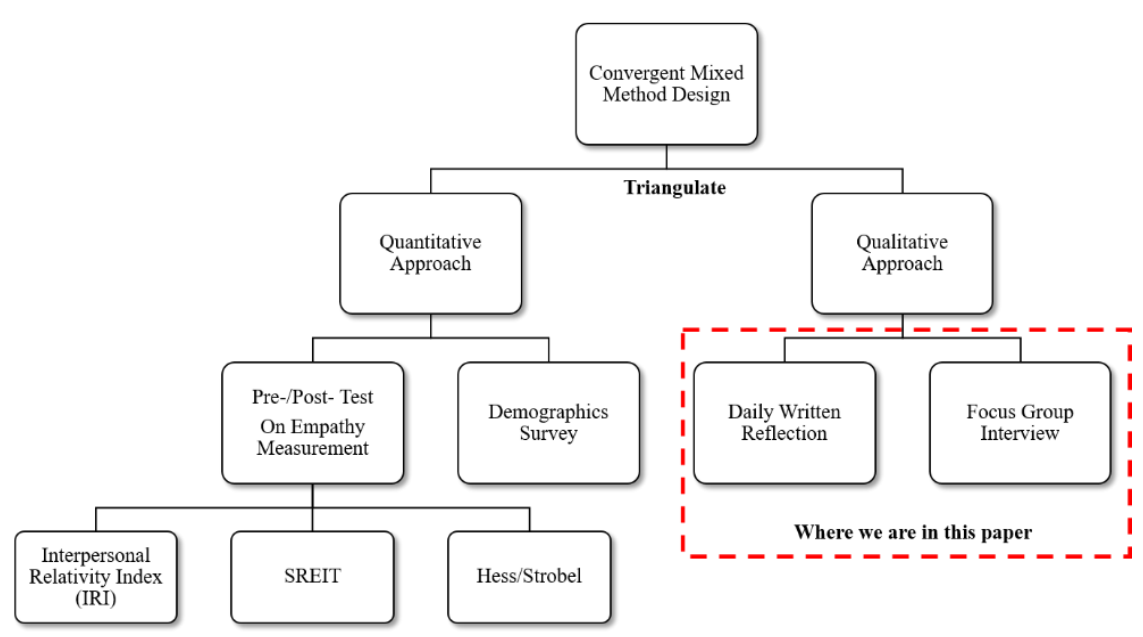

Figure 1. The convergent mixed-methods design for the pilot study

\subsection{Qualitative Data}

The students' written reflections are the primary source of qualitative data. The students completed on-site reflections throughout the service-learning experience. Complementarily, a focus group was conducted nine days after the students came back from the trip to obtain insight into their personal experiences, as well as review the research structures to improve upon future investigations. Both the written reflections and focus group data that inform the research study are not parts of the class requirements. Students were informed that their participation or responses would have no implications on the course grade or outcomes.

\section{$\underline{\text { Written reflections }}$}

The written reflections were collected across five days (from day 2 - day 6) on-site, throughout the service-learning experience. Differing prompts were given to the students to direct the written reflections, using the prompts as follows:

- Day 2-3: How has this experience helped me grow? How does this experience serve my education?

- Day 4-5: No prompt, write freely.

- On day 6: How does this experience impact empathy in engineering?

The written reflection data collected was transcribed into the NVivo 11 software. Each student was given a unique identifier to maintain personal information confidential. It is noted that the day 6 prompt overlaps significantly with the research question through directly asking the students whether they think the service-learning experience impacted their empathy. The data analysis of the day 6 data accounted for this by only including responses where the students explicitly link their thoughts on empathy to on-site experiences. 


\section{Focus group}

A semi-structured focus group was conducted nine days after the students returned from the service-learning experience. The students were asked to discuss their thoughts and the perceived connections between empathy and engineering. The pilot study was also used to inform appropriate structures and types of data that are suitable to analyze empathy within communityengaged learning. Due to this, both written reflections and focus group data were collected. During the analysis process, the research team agreed to put more focus on the qualitative written reflection data, in order to capture thick descriptions of personal thoughts from each day. The reflection data was written by each individual, taking time and effort to sit down and write their feelings both implicitly and explicitly, which required a high-level of scrutiny to analyze. Therefore, the major findings were drawn from the written reflections, while the focus group interview didn't provide additional findings, but reinforced the outcomes from the reflections data. Within the focus group data included, individual speakers are not identified and the data excerpts presented remain anonymous.

\subsection{Qualitative Analysis}

A constant comparative method was adopted to analyze the written reflections to contextualize the ways in which the students were impacted through the service-learning experience by thematic coding. [38]. This focus on students' development of empathy was informed by the framework from Decety \& Moriguchi [30] constructed by four components of empathy: affective sharing, self-awareness, mental flexibility \& perspective taking, and emotion regulation. During the coding process, the analysis team was open to emergent themes around the development of empathy. As a result of the thematic coding, the emergent categories include: personal development, emotional response, service-learning context, group dynamics, and local interactions. The coders used memoing to continually revisit and redefine the meaning of each category, as well as combing, comparing, and delineating themes.

The interpretive coding process is shown in Figure 2 and was performed as follows:

1. Empathy as described by the Decety \& Moriguchi neuroscience constructs comprised the primary categories in interpretive coding in line with the research question.

2. In parallel, the thematic coding process was initiated to interpret other emergent aspects of the data. One member of the research team (Coder 1, a female PhD student in Education) coded the data by memoing and adding appropriate categories.

3. A second coder (Coder 2, a male PhD student in Engineering) repeated step 2, independently.

4. After Coder 1 and Coder 2 finished coding, they continually compared each reference coded both in the Empathy category and the emergent categories and discussed them openly with Coder 3 (Assistant professor in Engineering Education). The definition of each category is collectively redefined through discussion around areas of agreement/disagreement within each other's codes. This process refines each previous category and directs the development of new categories.

5. Finally, Coder 1 and 2 compared all the categories with oversight and contributions from Coder 3 . Three of these emergent themes were determined to be closely related to the 
development of empathy, which is shown as the dashed box enclosed in Figure 2 and used to develop the findings.

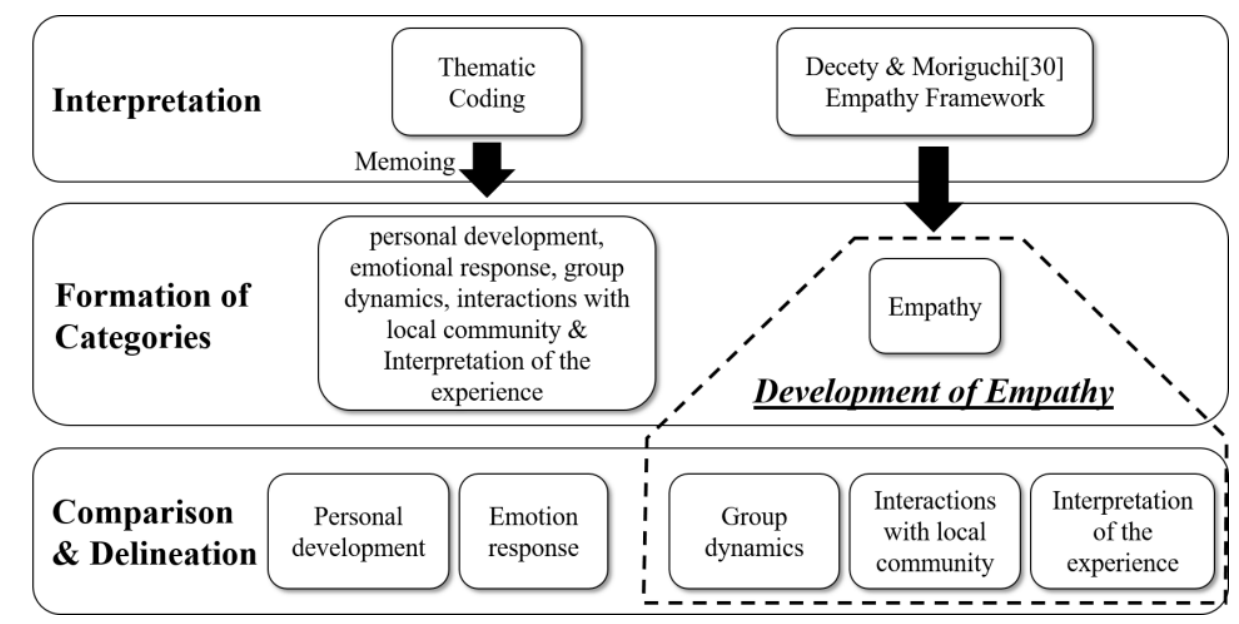

Figure 2. Interpretive Coding Process (adapted from [39])

\section{Data}

The data provides insight into the four constructs of empathy as they were manifested within the studied service-learning context. Table 4 highlights excerpts from the data that introduce each construct and provides examples from the student's reflections. As established, the reflections revealed that these four manifestations of empathy do not appear in isolation; often two or more of these constructs appear simultaneously in a single excerpt. The selected excerpts in Table 4 provide examples of how each construct is used in the analysis and reveals insight into empathy within a service learning context.

Our research findings focus on contexts that allow students to demonstrate the various ways that empathy can be manifested within service-learning contexts through written reflection. These contexts, provided by the service-learning trip to MdL, were coded into the categories mentioned above.

\section{Research Findings}

The analysis of the data collected within this study revealed three primary findings that support the development of empathy from within a service-learning context:

1. Group dynamics, or the interactions between university-based stakeholders

2. Interactions with local community, the context where students interact with local community members

3. Interpretation of the experience through reflection, which means students internalization of the personal experience through their own distinct perspective

Each of these findings supports deeper understanding of empathy within service-learning contexts around the four components: affective sharing, self-other awareness, mental flexibility 


\begin{tabular}{|c|c|c|c|c|}
\hline & 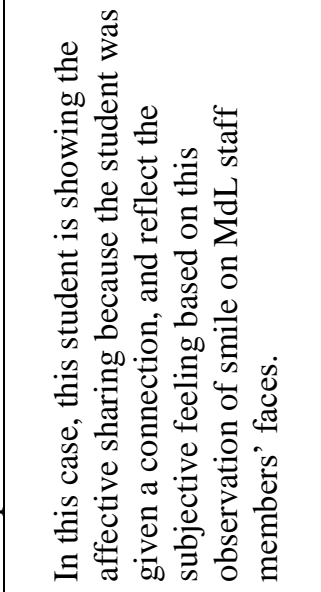 & 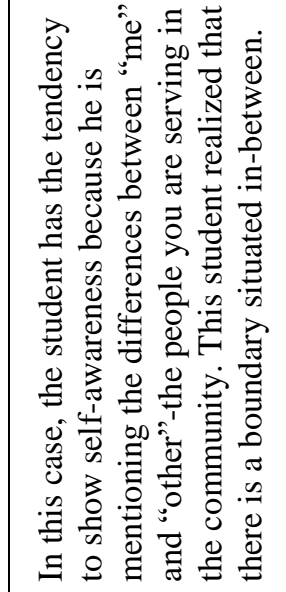 & 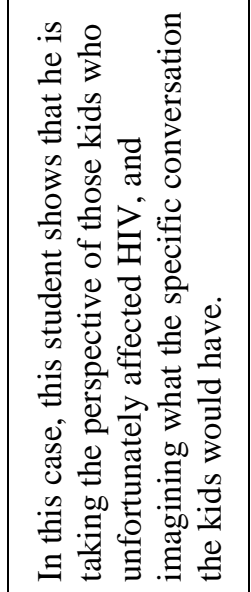 & 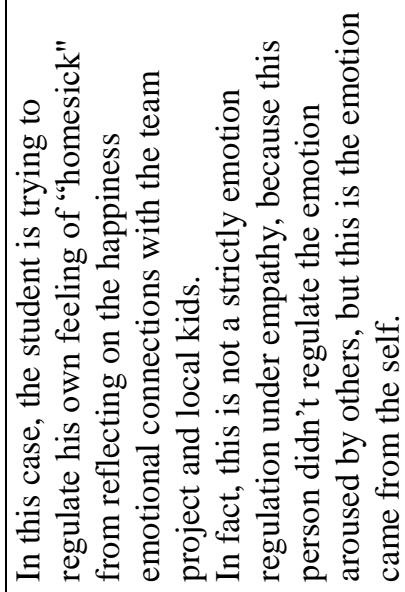 \\
\hline & 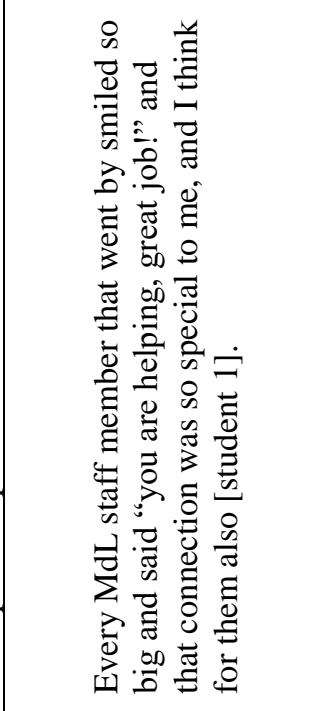 & 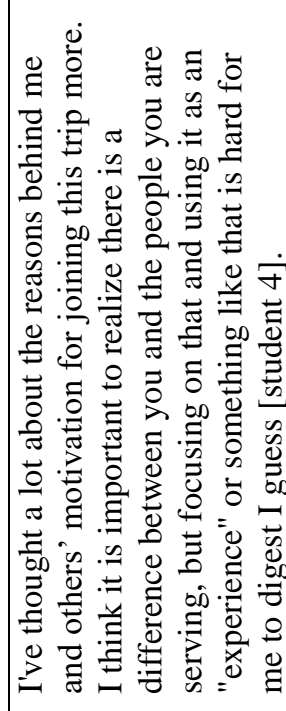 & 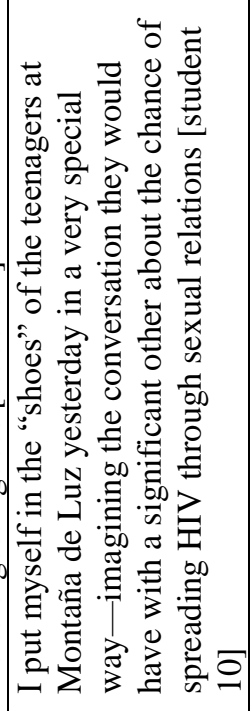 & 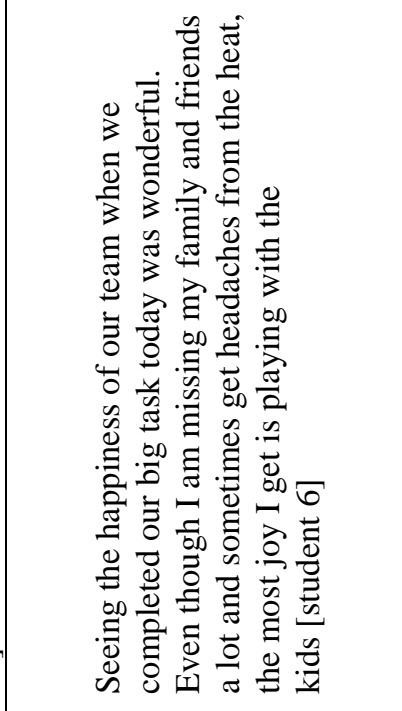 \\
\hline & 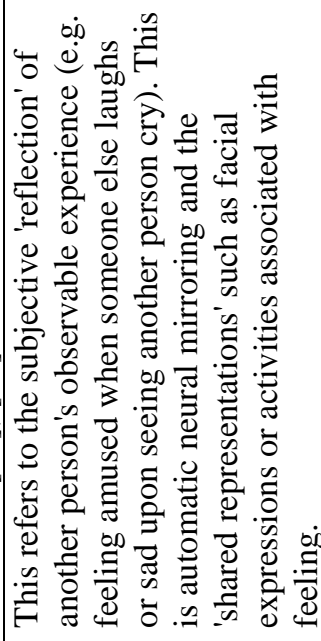 & 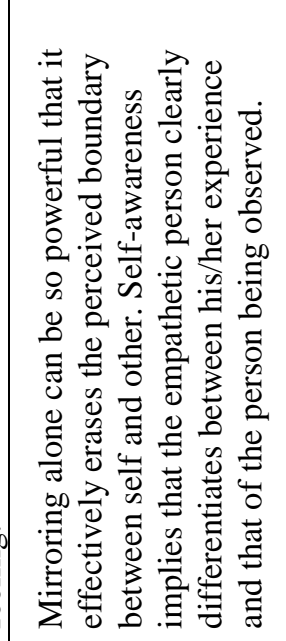 & 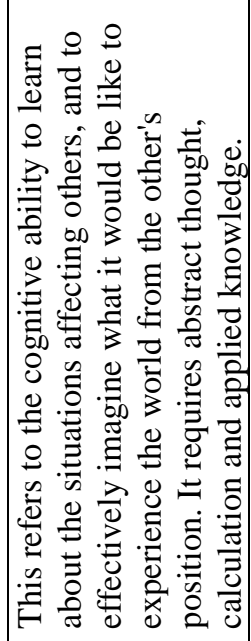 & 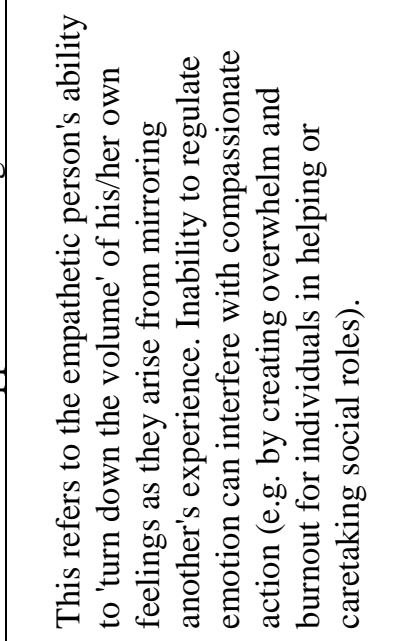 \\
\hline $\mid \begin{array}{l}0 \\
\tilde{0} \\
0 \\
0 \\
\text { : } \\
0 \\
0\end{array}$ & 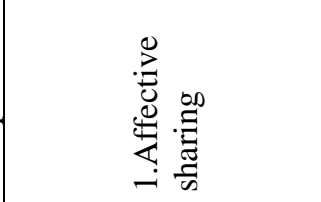 & 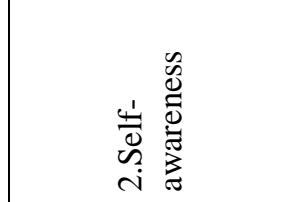 & 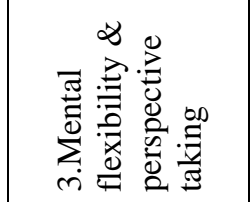 & 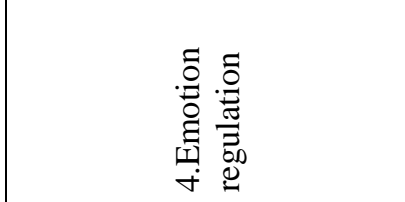 \\
\hline
\end{tabular}


\& perspective taking, and emotion regulation. The findings are presented with examples of excerpts from the written reflection data.

Finding 1 - group dynamics in the development of empathy

Group dynamics refers to interactions amongst the students and instructors. Project ownership, camaraderie, and interdependence were coded as subcategories within this finding. Project ownership represents the students' autonomy in handling the whole project on their own. Camaraderie represents deep trusting and open relationship between individuals. Interdependence represents the fact or condition of depending upon each other within mutual dependence [40]. This finding and its associated subcategory align with the team learning model developed by Miyake, which contains the following constructs [33]: interdependence, social cohesion, task cohesion, group potency, psychological safety.

Within Finding 1, the following three excerpts demonstrate how the three subcategories representing group dynamics can support the development of empathy. A first example, highlights affective sharing as it is manifested through camaraderie:

I feel like I'm bonding and getting to know this whole group more each day. I love the jokes we can all have together, the sense of each other that we have when someone is feeling down, and the gratitude of trying new things with each other [student 6].

As defined in Table 4, this student's reflection shows affective sharing through the process of bonding and developing camaraderie with the group. A second example, aligned with the focus group interview result, shows how group ownership facilitates perspective taking \& mental flexibility:

\footnotetext{
Also, a lot of us have never been in a setting like this where the project is entirely our own. I think we are also learned a lot about ownership and responsibility. Because the projects are our own we've also grown in our technical communication skills. In any project, especially when there is a language barrier, you have to be very clear about your ideas and plans. I've noticed myself being able to communicate my ideas more clearly to my team, others involved and other groups who are interested [student 4].
}

This excerpt illustrates that this student is taking the perspective of peers who, similarly, have never been responsible for delivering this type of project, and try to enhance their communication skills as they interacted with the others when working on the project. Hess et.al [41] also presented a similar concept that teamwork is a common factor that provides for the inclusion of empathy in engineering practice. This also aligns with the discussion during the focus group:

Being able to put yourself in other's shoes and understand their values and how they would feel about certain outcomes of the project - helps you connect to the actual project and feel a sense of ownership and drive toward getting it done and doing it correctly. I think that is ... when you connect with it and feel invested in it you do a much better job.

In addition, the third example suggests that interdependence can also support the opportunities for the development of empathy through self-awareness: 
I have found myself becoming more and more entrusting of those around me. I know how that I can trust them because they have proven their hard work ethic and dedication to the same cause that I have. In the past, while working on group projects, I often become easily frustrated when group members would stand around. I see now that this was because they didn't have the same drive that I had to complete the project and work hard in the final hour. However, here it is totally different. Everyone I am with is extremely dedicated to the work we are doing, most even more than me. I find this to be very impactful to my own learning as I am motivated by those around me [student 9].

Due to this person's prior frustrating group experience, realizing the interdependence brought up by the group illustrating the student's self-awareness. Therefore, by dedicating the mutual dependence and keeping motivation, this student found the entrusting group relationship was build up.

In addition, group dynamics is mediated through student-instructor interactions. Within servicelearning activities, the group dynamics can be different than those within a traditional classroom. This is due to the fact that standard barriers between instructors and students can be manifested in a less rigid manner within this informal learning setting. Here is one example that shows how opportunities for the development of empathy are realized by the students with an instructor:

Just talking to [instructors] and laughing with them makes me feel like they are my age. I really love their attitudes on things, they aren't bossy or they don't tell us what to do. They make us think, are really chill or intellectual people, and I'm glad to call them my friends. I'm so glad I can look up to them as role models and feel how big their hearts are [student 6].

This excerpt indicates that this student was given positive feedback by the instructor's behavior of affective sharing and other virtues as well. In fact, the instructors can play an important role in leveraging students' interests, as well the interests of other stakeholders', to enrich and strengthen the service-learning experience [42].

As we conclude the results from finding 1, there are key actors which appear to influence project ownership, camaraderie, and interdependence in group dynamics: peers and instructors. The relationships between and dynamics amongst peers and instructors are deepened through collaboration around the individual projects. By supporting the development of the project, the group dynamics are developed in ways that provide the context upon which empathy is manifested. The conceptual interactions between the actors and three aspects of group dynamics are shown in Figure 3. 


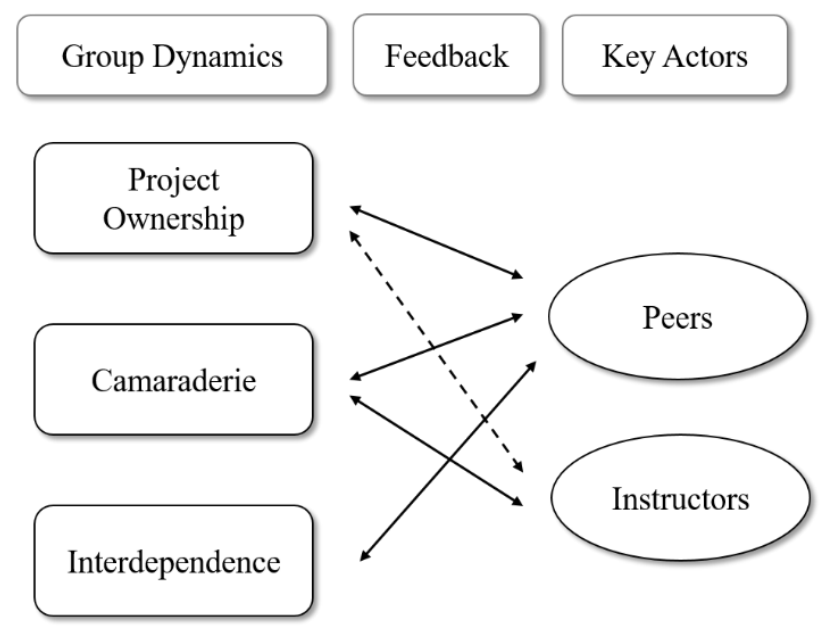

Figure 3. Group dynamics interactions with key actors

The arrows in Figure 3 represent an important element that emerged from the data: feedback through others and self-reflection. The influence of the group shows significance in providing feedback to the person who has not only observed or lived an experience but has also reflected upon it. The concept of feedback in this study, borrowed from the work of Lewin [43], is "a social learning and problem-solving process that generates valid information to assess deviations from desired goals". Specifically, within the students' development of empathy as this desired goal, existing models/frameworks and definition can be leveraged towards these outcomes. During this process, the individual can receive positive or negative feedback, often implicit but also explicit, through group dynamics, which can provide for an individual's development of empathy within service-learning contexts.

\section{Finding 2 -Interactions with the local community in the development of empathy}

Another mechanism that was found to be instrumental to development of empathy during this service-learning trip was spending time and interacting with the local people: in this case, the children in Montaña de Luz, the local staff on site at the center, and other local individuals within Honduras. Throughout the days dedicated to work on the service-learning projects (Days $2-6$ ), the students spent a portion of their day interacting with the Montaña de Luz youth, and a majority of the day working to make progress on their group projects. The data shows that through immersion within the local community the students reflected on multiple aspects of empathy simultaneously.

I just talked to one of the kids. I said she was muy bonita, and she jokingly repeated, "no, soy fea! Tue eres bonita, soy fea!" But I kept repeating that she was beautiful, intelligent, funny and kind. She still joked around and said "no, soy fea!" We played around a while, and the I felt the need to say again "eres bonita!" she refused at first ("soy fea!"), but when I went on to say genuinely that she is beautiful, funny, smart and kind - she just listened, with this eager smile on her face, like she was thirsty and was being filled. I don't know how much she gets told these truths about herself. Her medicine and the psychological issues she deals with mess with her emotions, and she can cause mischief. Perhaps this hampers others from affirming her in these truths about herself [student 10]. 
This reflection recounts a story about a student's perception of how a local child is feeling based on the observation of a smile through affective sharing. Then, the student reflects on how the young person refused to accept compliments through mental flexibility \& perspective taking. The student was able to realize that the psychological and physical issues may have affected this young person willingness in accepting affirmation, and others' willingness to affirm the children. In the end, we can see the student regulate emotion in this excerpt by telling the child again "you are beautiful". Through the whole process, this student shows awareness of self and other.

The data indicates that the environment and setting in which the local people live is substantially different from that in which the students live. This can potentially facilitate gains in empathy in differing ways than compared to the interactions that would arise within more familiar settings. Here are two excerpts illustrating the importance of students immersing themselves into the MdL community. The first example shows student's affective sharing, mental flexibility \& perspective taking, and self-awareness when reflecting on similarities with the kids in the center. A student seeks to relate these feelings:

I still don't know how typical citizens live, this seems to be a pretty special place. I do think getting to know these kids, seeing the mood swings, the sometime random behavior, has made me realize the hardships they go through. Above all, I think it is the similarities. Playing soccer with them, and see the same joy, focus, it really has allowed me to see how alike we are. And then consider the differences we have, and to know what they must feel [Student 2].

The second example shows the student's self-awareness, mental flexibility \& perspective taking, and emotion regulation when experiencing this situation around the light bulb. It provides for a realization around the difference between the students lived environment and the world of the MdL children. The student did not personally feel much excitement in changing the light bulbs, but chose to share laughter and enjoyment with the kids:

I also learned a lot about how something that may seem insignificant to me can mean the world to other people. I had to change light bulbs out with more efficient ones earlier, and once the kids found out what I was doing, they followed me around, point out bulbs to change, and even changed many of the bulbs themselves - all while laughing and screaming along the way. To me, the light bulbs were just mere light bulbs, but to these kids, they obviously meant much more [Student 13].

Within finding 2, differences between the students' personal background and local foreign community provided by the service-learning experience seemed to cause some shock to some of the student participants. According the cognitive mapping of service-learning experience as a theory of engagement, there are three social-psychology stages to the development of engagement: shock, normalization, and engagement [44]. Through interactions with the local community, the shock brought to the students seems to be strongly moderated by self-awareness within empathy. Here is the example of one student who exhibited affective sharing without selfawareness. As a result, this student appeared to blur the self-other boundaries and had a hard time regulating his/her emotions:

I also feel a little overwhelmed. I love every single kid here and I can't help but imagine how many kids are out there that need love. It makes me sad to imagine how an innocent child can grow up to be a gang member - completely desensitized to the killing of others or the safety of other people in general [student $1]$. 
We conclude from the data that interactions with the local people impact the university students in at least two ways: first, is the conflict of recognizing students as both a student-engineer onsite to deliver a service and an outsider that is present within the community; second, is the chance that they see the actual end users who are going to benefit from the engineering projects. Together, these interactions can facilitate opportunities to develop empathy. This finding is in good agreement with the literature on empathy in engineering and Zoltowski et.al's research on empathic design [22] where student designers who connect with the end user in informal settings can develop a broad understanding of stakeholders beyond scope of project. Moreover, this finding aligns with the conversation in the focus group:

I'd say with the projects we implemented - you can see where it's going to go and what it's affecting. Usually in engineering projects you don't get to see that and that was huge to see that the end user was an orphanage. It adds a different component since you're in the midst of it all you're more eager to get it done. In the engineering world if you can see the effect that's important to the project.

Finding 3-Interpretation of the experience through reflections towards the development of empathy

Finding 3 includes the different ways in which students can interpret and internalize the service learning experience and how that can result in the development of empathy. Through analysis of the written reflections, it is shown that individual students can focus on differing aspects of the service-learning experience. Each individual can potentially have an "a-ha"/eureka moment at different points during the experience, showing how an engineering service-learning experience can facilitate a unique platform for the development of empathy. For example, here are two excerpts where the reflections indicated potential for the development of empathy. The first student shows self-awareness and mental flexibility \& perspective taking when reflecting on changes in performance within the groups project:

I had a little more success within my group since I could actually understand them, and I would help them however I could, because that's what I wanted them to do for me. Yet, due to my difficulty communicating in general, in addition to the language barrier, I still found myself spending more time alone, when I would have rather have spent it helping others and getting to know them [Student 13].

The second student empathized with the artists who created the graffiti and expressed the public value through self-awareness, mental flexibility \& perspective taking:

On the drive back, I was looking out the window and saw graffiti written on rocks along the road. What stuck out to me the most was the fact it said "Jesus". This is something I've never seen in the U.S., and it made me think for a moment. In the U.S., I've only seen obscure artwork or vulgar phrases, but here I saw peaceful artwork in a place of such poverty [student 3].

The ways the same experiential learning setting are internalized can diverge when different individuals face the same setting. Here are example excerpts which discuss the field trip to the cigar factory where two students were inspired differently:

I didn't really enjoy the cigar factory itself (very smoky), but it was a wonderful opportunity to see what work was like for a lot of Hondurans in the area [Student 10]. 
We also saw another side of Honduras labor, the cigar Factory. In the US, there is such an emphasis on the individual when employment is considered. You are special, we need this kind of person, and etc. In a large factory like that, it is like part of some large machine. They are bussed in on school buses. There is odd propaganda-like photos on the wall with quotes like "my work satisfies me" or "do it for the good of the company". It is odd to see such groupthink mentality [Student 2].

These reflections have also shown the potential of service-learning as an active pedagogy that supports empathy. Within this service learning activity, the development of empathy was investigated as an implicit outcome of this learning experience. Hess \& Fila also concluded that outside of engineering practice, many aspects of first-hand experiences through service-learning can provide for personal development [31]. Even though empathy has been shown to consist of teachable skills [25], the delivery mechanisms are not limited to the classroom; Hess \& Fila [31] suggest that to develop empathy, one must be conscious through authentic and meaningful experiential learning activities.

\section{Focus group}

The focus group was useful in reinforcing the results obtained from the written reflections. The students agreed that the emotional connections helped them to get through on-site challenges. The camaraderie and trust were enhanced through high pressure around the shared goals of delivering the projects to the MdL community in time. The students also reflected that during the service-learning experience, they learned that understanding end-users' perspective is an important skill. There are three reasons: first, it is powerful to see the actual end-user and the impact the engineering solution can provide. Second, being able to observe the others' needs instead of asking directly "what do you want?" is more helpful. Finally, being aware of the limitations that individual abilities can actually help the community is significant.

\section{Discussion}

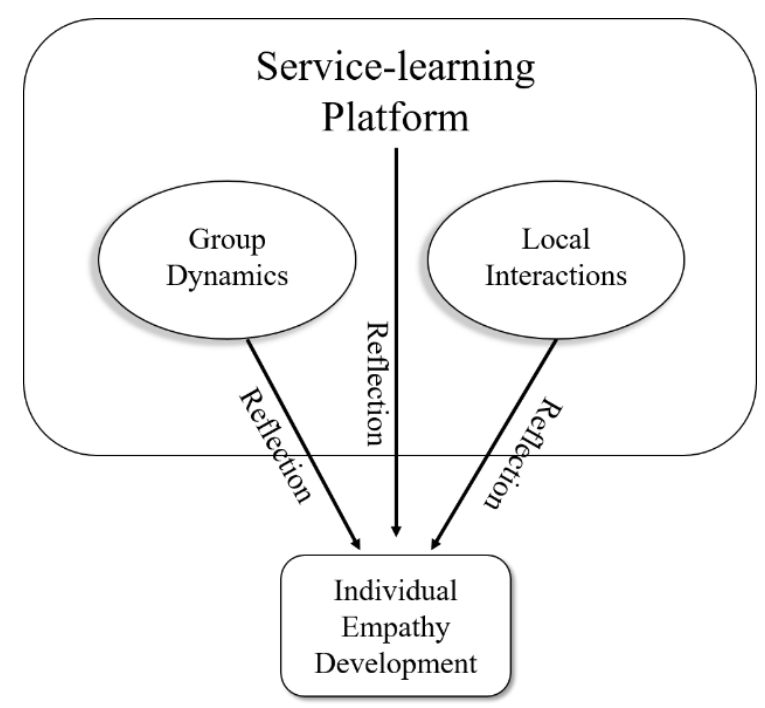

Figure 4. Service-learning as the platform for the development of empathy

The findings presented above are integrated into a diagram, shown in Figure 4, that describes the relationship between the findings, serving as a scaffolding that can support the development of 
empathy in undergraduate students through engineering service-learning. Within a servicelearning platform, there are at least two critical elements that facilitated the potential for the development of empathy: group dynamics (where a student interacts with university peers and instructors) and interactions with local community. The arrows in Figure 4 represent the selfreflection leading towards learning outcomes around empathy. Each individual's empathy development is internalized and constructed differing self-refection within the service-learning platform.

According to the findings, the development of empathy in engineering service-learning is provided by three facets of the trip: service-learning pedagogy, experience settings, and reflective observation. First, this service-learning trip was designed by particular activities to provide the platform for the students' growth in professional skills. The specific activities of this service-learning trip included: implementing group projects through real-world practice, performing community service within the MdL center, spending time with the local children affected by HIV/AIDS, a field trip to a cigar factory, and visiting the local university. These different community-based experiences helped students to be more engaged with the Montaña de Luz setting. These activities were constantly mentioned within the reflections highlighting experiences with locals, instead of focusing only on their engineering/educational project. Studies have shown that the complementary pedagogies of project-based learning and servicelearning merge, there is potential for student development on three developmental processes: cognitive, social and moral levels [11]. Within the combination of project-based and servicelearning, students can be connected to a community's need which provides sociocultural context. This can stimulate their development of empathy from the cognitive and social levels.

Second, the setting of this service-learning trip provided students with a substantially different experience than which they are familiar. There are two challenges brought by this trip: foreignness and language. Here are two excerpts to der to presents the impact on the students from the unfamiliar foreign situation:

I'm learning how to improvise and I'm being challenged to use my own head because I don't have access to Google for answers or Amazon for extra supplies. This is helping me be a more creative engineer [Student $10]$.

\footnotetext{
Not having access to a phone to talk to anyone back home really forced me to do some self-reflection on my life, and my attitude in my daily life. I think that a phone allows us to share things with those we care about, but is then overused and can so easily become a malicious tool in one's life...I turned my phone's wifi on for a couple minutes to see if it would work and it did. But I'm not ready to go back to that just yet. I want to keep this trip the way it is, so I deleted the notifications and turned my wifi back off. Thank you again [Student 11].
}

Immersion within the foreign community can provide the students with insight into how the local people experience their everyday life. With the understanding of the lived experiences and enduser perspective, it can still be challenging for students to take actions and design with the actual engineering solution. In this case, these challenges and new understandings were developed through self-reflection by putting oneself into the authentic perspective of serving the community. This allows students to potentially develop deeper knowledge about the local challenges outside of the university classroom settings, where can sometimes be isolated from real-world scenarios. The second barrier is the language. The local people in the MdL 
community speak Spanish, but most of the students are only English-speaking. Here are two excerpts from one student who reflected on language experience during two different days:

(Day 4) I got to connect with the kids even more today and it made me realize just how much they are doing for us. They are the reason I want to come back for more. If my Spanish was better, I would articulate to them just how much of an impact they've had on me and how special they are to all of us.

(Day 5) Being able to connect with the kids through a language barrier, as well as my classmates with a daunting task. However, by the end of this trip, I hardly have any insecurities, and have no real problems with anyone at all [Student 11].

The language barrier enables this student to think about the connection that can still be developed with the kids, despite the language, through affective sharing. The process of working through this language barrier also helped the student grow personally, by improving his or her communication skills as we can see the same person developing across different days through reflections within this foreign environment.

Third, during the service-learning trip, the students had the chance to perceive their own knowledge and reflectively observe new experiences. The development of empathy can be potentially overlaid onto the process of Kolb's experiential learning theory [43]. Immersed within the foreign community, engineering students' learning experience can be developed through the cycle of concrete experience, reflective observation, abstract conception, and active experimentation as shown in Figure 5 [4].

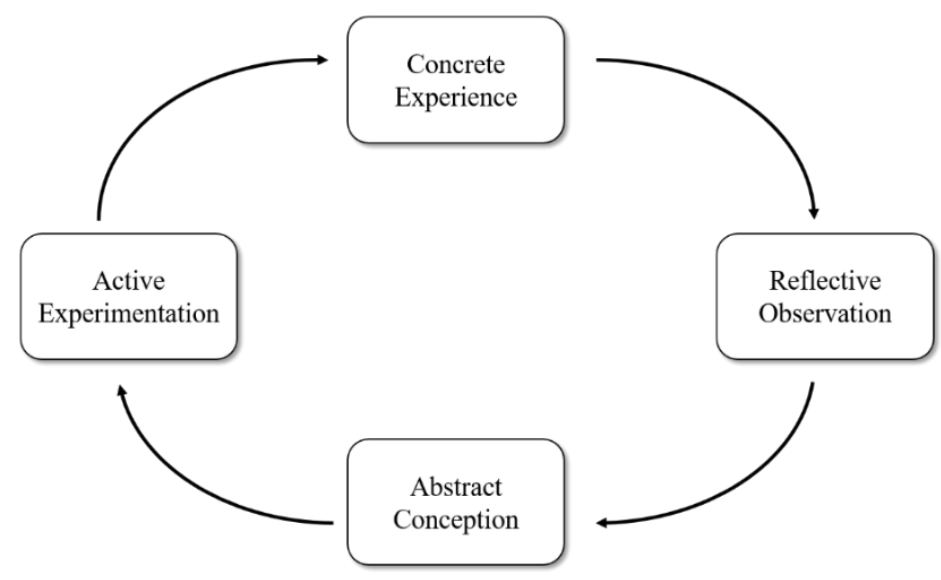

Figure 5. Adapted from Kolb's experiential learning cycle[4], [42], [43]

Within this experiential learning cycle, the concrete experience was provided by the servicelearning activity, followed by the stage of individual's reflective observation into abstract conception. Finding 3 describes how internalization from self-reflection in the service-learning experience - the a-ha/eureka moment - can be generated in different ways from the same servicelearning activity. This leads to the importance of an effective educational design around the proper settings of the service-learning as the experiential platform upon which students can be supported during the development of empathy, as well as other important professional skills that students can potentially develop within a service-learning context. 


\section{Limitations}

In this pilot study, two limitations must be acknowledged within the written reflection prompts, and participants selection. By asking the students certain question for day 2-3 and day 6, the reflection responses written are leading/biasing the students around the concept of personal growth (day 2-3), and the development of empathy in day 6. This limitation was overcome by only including day 6 data when the written reflection explicitly linked the development of empathy to on-site activities. The construction of the prompts could be refined to not lead or bias the participants. Through this pilot study, what kind of prompts and reflections are helpful for students needs more rigorously designed research. For example, when there are no prompts asked through day 4-5, student wrote their reflections mainly focused on their group project and struggles. The data suggests it is also possible that empathy development can be obtained as a result of writing responses to the reflection prompts. The authors will further explore the role of written reflection in service-learning trip in engineering, as well as other humanitarian engineering courses and programs context. The prompts themselves have been shown effective in encouraging the students to reflect and can serve as an educational intervention.

Second, as for the participants selection, all participants involved are all white students. The inclusion of more diverse perspectives should also be considered. Also, the participating students self-selected into this course. This can introduce a selection bias from the qualitative data if those students are more reflective, willing or ready to serve, or more empathic compared with peer engineering students who did not select this type of course. Further study needs to be performed not only including more diverse students according to their demographic background, but also students both with and without service-leaning experience. To make the best use of the servicelearning platform, there can be the possibility that the volunteering motivation in students when they participate can both be beneficial to this course, and to the local community (where they do service). According to Building Partnerships with College Campuses: Community Perspectives [45] summit report, "...mandating engagement activities devalues them and can lead to work done in a perfunctory manner. Because there are real costs to community organizations for engaging with campuses, they do not place organizational priority on creating what they call 'make-work' for students who just want to get their hours in", such insights have touched and debated upon this direction of possibility. Also, as long as those service-learning credit-bearing courses remain elective, the students are more likely to enroll based on their own motivation, which may suggest this case study has the typical participants within service-learning contexts.

\section{Future work}

Based on the pilot nature of this analysis, the results require further investigation. A next step includes completing the analysis of the quantitative data from this trip to understand the implications of the mixed methods approach. The combination of quantitative and qualitative elements can provide a holistic approach. Future study aims to contextualize empathy as studied here within the model of empathy in engineering. The systemic model for empathy in engineering has been developed through the synthesis of the literature from psychology, neurobiology, social work, and engineering, which positions empathy as a teachable and learnable skill; a critically reflected-upon practice orientation; and a professional way of being [25]. Another conceptual model of empathy development from the individual level has been set up, 
which draws the cyclical relationship between different aspects of empathy [31]. Additionally, Hess \& Fila [31] have studied service-learning as one of the five important contexts to impact empathy, other contexts are design thinking, collaboration, communication and ethics education. These efforts, although are not used as a framework for this research, alongside continued can support an understanding service-learning as a platform for empathy in engineering education.

Impact on local community is also critical within the context of service learning efforts. This paper did not include the impact of service-learning from the community perspective, but this should be considered as part of service-learning project evaluation to ensure the mutual benefit and reciprocity between service and learning. Efforts to include the perspective of the community must be a part of future studies.

\section{Conclusion}

As the National Academy of Engineering's Engineer of 2020 [46] seeks to change engineering stereotypes from a masculine framework to a holistic image, our study shows that empathy in engineering education can contribute to the community through opportunities to enhance the role of humanitarian perspectives. This pilot study has yielded findings through qualitative analysis of engineering student reflections on a service-learning trip: group dynamics, interactions with local community, and self-reflection. Each aligns with the four components of the manifestation of empathy: affective sharing, emotion regulation, self-awareness, and mental flexibility \& perspective taking to analyze the potential for the development of empathy through written reflection. 


\section{References}

[1] D. Jonassen, J. Strobel, and C. B. Lee, "Everyday problem solving in engineering: Lessons for engineering educators," J. Eng. Educ., vol. 95, no. 2, pp. 139-151, 2006.

[2] J. Walther, S. E. Miller, and N. N. Kellam, "Exploring the role of empathy in engineering communication through a transdisciplinary dialogue," in 119th ASEE Annual Conference and Exposition, 2012.

[3] National Academy of Engineers, Educating the Engineer of 2020: Adapting Engineering Education to the New Century. Washington, D.C.: National Academies Press, 2005.

[4] K. Litchfield, A. Javernick-Will, and A. Maul, "Technical and Professional Skills of Engineers Involved and Not Involved in Engineering Service," J. Eng. Educ., vol. 105, no. 1, pp. 70-92, Jan. 2016.

[5] H. J. Passow and C. H. Passow, "What Competencies Should Undergraduate Engineering Programs Emphasize? A Systematic Review,” J. Eng. Educ., vol. 106, no. 3, pp. 475-526, Jul. 2017.

[6] J. L. Huff, C. B. Zoltowski, and W. C. Oakes, "Preparing Engineers for the Workplace through Service Learning: Perceptions of EPICS Alumni: Preparing Engineers for the Workplace through Service Learning," J. Eng. Educ., vol. 105, no. 1, pp. 43-69, Jan. 2016.

[7] A. Furco, "Issues of definition and program diversity in the study of service-learning," Stud. Serv.-Learn. Innov. Educ. Res. Methodol., pp. 13-33, 2003.

[8] R. G. Bringle and J. A. Hatcher, "A service-learning curriculum for faculty," Mich. J. Community Serv. Learn., vol. 2, pp. 112-122, 1995.

[9] E. J. Coyle, L. H. Jamieson, and L. S. Sommers, "EPICS: A model for integrating servicelearning into the engineering curriculum.," Mich. J. Community Serv. Learn., vol. 4, pp. 8189, 1997.

[10] A. R. Bielefeldt, K. G. Paterson, and C. W. Swan, "Measuring the value added from service learning in project-based engineering education," Int. J. Eng. Educ., vol. 26, no. 3, pp. 535-546, 2010.

[11] A. Johri and B. M. Olds, Eds., Cambridge handbook of engineering education research. New York, NY, USA: Cambridge University Press, 2014.

[12] J. Eyler, D. E. Giles Jr, C. M. Stenson, and C. J. Gray, "At a glance: What we know about the effects of service-learning on college students, faculty, institutions and communities, 1993-2000," 2001.

[13] D. Delaine, J. Cardoso, J. Walther, "A boundary spanner intervention for increasing community engagement outcomes - Phase 1: Framing case studies in context," in 2014 International Conference on Interactive Collaborative Learning (ICL), 2014, pp. 571-578.

[14] D. A. Delaine, J. R. Cardoso, and J. Walther, "Qualitative Analysis of BoundarySpanning Implications within Interviews of Engagement Stakeholders," 2015 ASEE Annu. Conf. Expo., pp. 26.1289.1-26.1289.16, Jun. 2015.

[15] K. E. Gerdes, E. A. Segal, and C. A. Lietz, "Conceptualising and Measuring Empathy," Br. J. Soc. Work, vol. 40, no. 7, pp. 2326-2343, 2010.

[16] J. Decety and P. L. Jackson, "The functional architecture of human empathy," Behav. Cogn. Neurosci. Rev., vol. 3, no. 2, pp. 71-100, 2004.

[17] J. Rifkin, The Empathic Civilization: The Race to Global Consciousness in a World in Crisis, First Edition edition. New York: TarcherPerigee, 2009.

[18] L. McHugh and I. Stewart, The self and perspective taking: Contributions and applications from modern behavioral science. New Harbinger Publications, 2012. 
[19] "empathy | Definition of empathy in English by Oxford Dictionaries," Oxford Dictionaries | English. [Online]. Available:

https://en.oxforddictionaries.com/definition/empathy. [Accessed: 25-Apr-2018].

[20] M. H. Davis, Empathy: A social psychological approach. Boulder, CO, US: Westview Press, 1994.

[21] D. M. Riley and Y. Lambrinidou, "Canons against cannons," in Social justice and the engineering ethics imaginary. ASEE Annual Conference, Seattle, WA, 2015.

[22] C. B. Zoltowski, W. C. Oakes, and M. E. Cardella, "Students' Ways of Experiencing Human-Centered Design," J. Eng. Educ., vol. 101, no. 1, pp. 28-59, Jan. 2012.

[23] J. L. Hess, N. D. Fila, and S. Purzer, "The Relationship Between Empathic and Innovative Tendencies Among Engineering Students," Int. J. Eng. Educ., vol. 32, no. 3, pp. 1236-1249, 2016.

[24] J. Strobel, J. Hess, R. Pan, and C. A. Wachter Morris, "Empathy and care within engineering: qualitative perspectives from engineering faculty and practicing engineers," Eng. Stud., vol. 5, no. 2, pp. 137-159, Aug. 2013.

[25] J. Walther, S. E. Miller, and N. W. Sochacka, "A Model of Empathy in Engineering as a Core Skill, Practice Orientation, and Professional Way of Being," J. Eng. Educ., vol. 106, no. 1, pp. 123-148, 2017.

[26] P. T. Robbins, "The reflexive engineer: perceptions of integrated development," J. Int. Dev., vol. 19, no. 1, pp. 99-110, Jan. 2007.

[27] M. Kouprie and F. S. Visser, "A framework for empathy in design: stepping into and out of the user's life," J. Eng. Des., vol. 20, no. 5, pp. 437-448, Oct. 2009.

[28] M. J. Riemer, "Integrating emotional intelligence into engineering education," World Trans. Eng. Technol. Educ., vol. 2, no. 2, pp. 189-194, 2003.

[29] J. S. Busby and M. Coeckelbergh, "The social ascription of obligations to engineers," Sci. Eng. Ethics, vol. 9, no. 3, pp. 363-376, 2003.

[30] J. Decety and Y. Moriguchi, "The empathic brain and its dysfunction in psychiatric populations: implications for intervention across different clinical conditions," Biopsychosoc. Med., vol. 1, no. 1, p. 22, 2007.

[31] J. L. Hess and N. D. Fila, "The development and growth of empathy among engineering students," in 123rd ASEE Annual Conference and Exposition, 2016.

[32] J. L. Hess, J. Strobel, and A. O. Brightman, "The Development of Empathic PerspectiveTaking in an Engineering Ethics Course," J. Eng. Educ., vol. 106, no. 4, pp. 534-563, Oct. 2017.

[33] R. K. Sawyer, The Cambridge handbook of the learning sciences. Cambridge University Press, 2005.

[34] J. W. Creswell and V. L. P. Clark, Designing and Conducting Mixed Methods Research. SAGE Publications, 2017.

[35] M. H. Davis, "A multidimensional approach to individual differences in empathy," 1980.

[36] N. S. Schutte et al., "Development and validation of a measure of emotional intelligence," Personal. Individ. Differ., vol. 25, no. 2, pp. 167-177, Aug. 1998.

[37] J. L. Hess, J. Strobel, R. (Celia) Pan, and C. A. W. Morris, "Insights from industry: a quantitative analysis of engineers' perceptions of empathy and care within their practice," Eur. J. Eng. Educ., vol. 42, no. 6, pp. 1128-1153, Nov. 2017.

[38] G. Gibbs, Analyzing Qualitative Data, London, England: SAGE Publications, Ltd, 2018. 
[39] J. Walther, N. Kellam, N. Sochacka, and D. Radcliffe, "Engineering competence? An interpretive investigation of engineering students' professional formation," J. Eng. Educ., vol. 100, no. 4, pp. 703-740, 2011.

[40] K. Smith, S. Sheppard, D. Johnson, and R. Johnson, "Pedagogies of Engagement:

Classroom-Based Practices,” J. Eng. Educ., vol. 94, no. 1, pp. 87-101, Jan. 2005.

[41] J. L. Hess, J. E. Sprowl, R. Pan, M. Dyehouse, C. A. W. Morris, and J. Strobel, "Empathy and caring as conceptualized inside and outside of engineering: Extensive literature review and faculty focus group analyses," in American Society for Engineering Education, 2012.

[42] A. Johri and B. M. Olds, "The Cambridge Handbook of Engineering Education Research and Reflections on the Future of the Field," J. Eng. Educ., vol. 103, no. 3, pp. 363-368, Jul. 2014.

[43] D. A. Kolb, Experiential learning: Experience as the source of learning and development. FT press, 2014.

[44] K. A. Rockquemore and R. Harwell Schaffer, "Toward a theory of engagement: A cognitive mapping of service-learning experiences," Mich. J. Community Serv. Learn., vol. 7, no. $1,2000$.

[45] S. Leiderman, A. Furco, J. Zapf, and M. Goss, "Building Partnerships with College Campuses: Community Perspectives.," 2002.

[46] National Academy of Engineers, The Engineer of 2020: Visions of Engineering in the New Century. Washington, D.C.: National Academies Press, 2004. 